\title{
Early intervention
}

\section{A foundation for lifelong violence prevention}

\section{Sarah Skeen, Mark Tomlinson, Catherine L Ward, Lucie Cluver and Jamie M Lachman*}

skeen@sun.ac.za

http://dx.doi.org/10.4314/sacq.v51i1.1

High levels of violence affect every family in South Africa. Exposure to violence starts early, in both the home and community. There are high levels of physical abuse of children, ${ }^{1}$ and the national under-five homicide rate is more than double that of other low- and middle-income countries. ${ }^{2}$ Rates of violence are particularly high in poorer communities in the country, and many children already made vulnerable by poverty are also at risk from increased exposure to violence. ${ }^{3}$

This is concerning, given the far-reaching consequences of violence. Children affected by violence run the risk of experiencing long-lasting effects on their health and developmental outcomes. For example, harsh physical abuse during childhood has been linked to increased rates of depression and attempted suicide. ${ }^{4}$ Affected children are also more likely to engage in harmful use of substances and risky sexual behaviour, and become HIV-infected. ${ }^{5}$ Perhaps most concerning is evidence of a cycle of violence: a child exposed to violence is more likely to engage in violent behaviour, rape and intimate partner violence during later life, ${ }^{6}$ bully other children, ${ }^{7}$ engage in youth violence and delinquency, ${ }^{8}$ and become an abusive parent, ${ }^{9}$ while also being more at risk of abuse or victimisation as an adult. ${ }^{10}$

Risk for violence perpetration is complex and driven by broader societal and cultural drivers, community

* Sarah Skeen and Mark Tomlinson are with the Centre for Public Mental Health, Department of Psychology, Stellenbosch University. Catherine Ward is with the Department of Psychology and Safety and Violence Initiative at the University of Cape Town. Lucie Cluver is with the Department of Social Policy and Intervention, University of Oxford, and the Department of Psychiatry and Mental Health, University of Cape Town. Jamie Lachman is with the Department of Social Policy and Intervention at Oxford University. factors, relationships with family and peers, and individual characteristics. ${ }^{11}$ There is very little research from South Africa and other low- and middle-income countries on violence and its link with childhood experiences. In high-income settings, however, it has been shown that key predictors of violent behaviour include early childhood factors such as hyperactivity and parental attachment, parenting problems and family conflict. ${ }^{12}$ We also know that the effects of violence exposure are likely magnified in unstable and volatile family contexts, ${ }^{13}$ and that many of the risk factors for early violence also predict intimate partner and sexual violence. ${ }^{14}$ Finally, we have a growing understanding of the relationship between early negative experiences and brain development, and how chronic 'toxic stress' may lead to difficulties in self-regulation, poor control of emotions, and aggressive behaviour in later life. ${ }^{15}$

This evidence suggests that primary prevention initiatives for violence perpetration should start early - during pregnancy and in early childhood. Indeed, the World Health Organization recognised the development of nurturing relationships between infants and their caregivers as the first 'best buy' in violence prevention. ${ }^{16}$ Having early secure and caring relationships is central to the development of a range 
of social skills that lay the groundwork for successful interpersonal relationships in later life. ${ }^{17}$ While there are limited evaluated early intervention programmes for violence prevention, there is some evidence from South Africa that home-based interventions can promote secure child attachment and better mother-child interaction. For example, the Thula Sana project, which took place in Khayelitsha, showed that home-visiting by lay health workers during pregnancy and the first six months after birth promoted maternal sensitivity and resulted in higher rates of secure infant attachment. ${ }^{18}$

However, given the complex, multi-layered causality of violent behaviour, focusing solely on early interventions is unlikely to have a sustained impact on preventing violence, particularly in countries of extremely high burden such as South Africa. Early intervention should not be seen as a magic bullet, and should rather form part of a suite of interventions across the lifespan. Multiple sectors and stakeholders should be involved in the development and implementation of evidence-based policies and programming that promote non-violent conflict resolution, gender equality and poverty reduction. There are several examples of primary prevention initiatives to guide the development of these interventions. After infancy, parent training programmes show promise for helping parents reduce behavioural problems (including aggression) in young children (under age 10), although evidence for programmes that work for older children is growing. ${ }^{19}$ There is evidence that school-based programmes can prevent interpersonal violence among children and youths of schoolgoing age. ${ }^{20}$ Teaching young children and adolescents life skills (particularly for non-violent conflict resolution) has a strong evidence base for preventing violence. ${ }^{21}$ Schools that emphasise academic achievement also help to prevent violence and other risk behaviours. ${ }^{22}$ After-school activities for children and adolescents that promote skills and are well-supervised are key interventions that allow for positive youth development. ${ }^{23}$ Interventions that reduce misuse of alcohol and other substances are critical, ${ }^{24}$ as are community-based programmes that address key risk factors. ${ }^{25}$
Early intervention provides the foundation for preventing violence in South Africa. It is crucial that children are given the opportunity to thrive in safe and nurturing environments throughout their childhood. Perhaps activist Frederick Douglass said it best: 'It is easier to build strong children than to repair broken men.'

5

To comment on this article visit

http://www.issafrica.org/sacq.php

\section{Notes}

1 L Richter and A Dawes, Child abuse in South Africa: rights and wrongs, Child Abuse Review, 17, 2008, 79-93.

2 M Seedat et al, Violence and injuries in South Africa: prioritising an agenda for prevention, Lancet, 374:9694, 2009, 1011-1022.

$3 \mathrm{H}$ Coovadia et al, The health and health system of South Africa: historical roots of current public health challenges, Lancet, 374, 2009, 817-834.

4 RE Norman et al, The long-term health consequences of child physical abuse, emotional abuse, and neglect: a systematic review and meta-analysis, PloS Medicine, 9:11, 2012, e1001349.

$5 \quad$ H Dubowitz and S Bennett, Physical abuse and neglect of children, Lancet, 369:9576, 2007, 1891-1899; R Mills et al, Child abuse and neglect and cognitive function at 14 years of age: findings from a birth cohort, Pediatrics, 127:1, 2011, 4-10; C Mock et al, Child injuries and violence: the new challenge for child health, Bulletin of the World Health Organization, 86:6, 2008, 420; L Richter et al, Reported physical and sexual abuse in childhood and adult HIV risk behaviour in three African countries: findings from Project Accept (HPTN-043), AIDS and Behavior, 18:2, 2014, 381-389.

6 R Huesmann, The contagion of violence: the extent, the processes and the outcomes, in Social and Economic Costs of Violence: Workshop Summary, Washington DC: National Academies Press, 2012; S Mathews and P Benvenuti, Violence against children in South Africa: developing a prevention agenda, in South African child gauge 2014: end the cycle of violence, Cape Town: Children's Institute, University of Cape Town, 2014, 26-34.

7 E Chaux, A Molano and P Podlesky, Socio-economic, sociopolitical and socio-emotional variables explaining school bullying: a country-wide multilevel analysis, Aggressive Behavior, 35:6, 2009, 520-529.

8 CL Ward, Youth violence, in PD Donnelly and CL Ward (eds.), The Oxford textbook of violence prevention: epidemiology, evidence and policy, Oxford: Oxford University Press, 2015, 27-34.

9 H Dubowitz and S Bennett, Physical abuse and neglect of children, Lancet, 369:9576, 2007, 1896.

10 LM Renner and KS Slack, Intimate partner violence and child maltreatment: understanding intra- and intergenerational connections, Child Abuse \& Neglect, 30:6, 2006, 599-617.

11 World Health Organization (WHO), World report on violence and health, Geneva: WHO, 2002. 
12 JD Hawkins et al, A review of predictors of youth violence, in R Loeber and D Farrington (eds.), Serious \& violent juvenile offenders: risk factors and successful interventions, Thousand Oaks: Sage Publications, 1998, 106-146.

13 SP Walker et al and the International Child Development Steering Group, Child development: risk factors for adverse outcomes in developing countries, Lancet, 369:9556, 2007, 145-157.

$14 \mathrm{WHO}$, Preventing intimate partner and sexual violence against women: taking action and generating evidence, Geneva: WHO, 2010.

15 C Bowers and A Dawes, Young children: preventing physical abuse and corporal punishment, in South African child gauge 2014: end the cycle of violence, Cape Town: Children's Institute, University of Cape Town, 2014, 58-64.

16 WHO, Global status report on violence prevention 2014 , Geneva: WHO, 2014.

17 JP Shonkoff and D Phillips, From neurons to neighborhoods: the science of early childhood development, Washington DC: National Academy Press, 2000.

18 PJ Cooper et al, Improving quality of mother-infant relationship and infant attachment in socioeconomically deprived community in South Africa: randomised controlled trial, British Medical Journal, 338, 2009, b974.

19 J Barlow, Preventing child maltreatment and youth violence using parent training and home visiting programmes, in PD Donnelly and CL Ward (eds.), The Oxford textbook of violence prevention: epidemiology, evidence and policy, Oxford: Oxford University Press, 2015, 133-140.

20 WHO, Preventing intimate partner and sexual violence against women: taking action and generating evidence, Geneva: WHO, 2010, 39.

$21 \mathrm{WHO}, \mathrm{Global}$ status report on violence prevention 2014, Geneva: WHO, 2014, 27.

22 AS Masten and JD Coatsworth, The development of competence in favorable and unfavorable environments: lessons from research on successful children, American Psychologist, 53, 1998, 205-220.

23 JA Durlak et al, Developing and improving after-school programs to enhance youth's personal growth and adjustment: a special issue of AJCP, Am J Community Psychol, 45, 2010, 285-293.

$24 \mathrm{WHO}$, Global status report on violence prevention 2014, Geneva: WHO, 2014, 34.

25 A Harvey, C Garcia-Moreno and A Butchart, Primary prevention of intimate-partner violence and sexual violence: background paper for WHO expert meeting May 2-3, 2007, Geneva: WHO, 2007. 